\title{
Metabolic Risk Factors and Cardiovascular Safety in Ketamine Use for Treatment Resistant Depression
}

This article was published in the following Dove Press journal:

Neuropsychiatric Disease and Treatment

Joanna Szarmach (D)

Wiesław Jerzy Cubała (ID

Adam Włodarczyk (i)

Maria Gałuszko-

Węgielnik (i)

Department of Psychiatry, Faculty of Medicine, Medical University of Gdańsk, Gdańsk, Poland
Correspondence: Adam Włodarczyk Department of Psychiatry, Faculty of Medicine, Medical University of Gdansk, 7 Dębinki Street, Building 25, Gdansk 80-952, Poland

Email aswlodarczyk@gumed.edu.pl
Introduction: Ketamine exhibits antidepressant properties in treatment-resistant depression (TRD) with some concern over its cardiovascular safety and tolerability issues. This paper reports on the cardiovascular safety in short-term intravenous ketamine treatment in TRD inpatients with major depressive disorder (MDD) and bipolar disorder (BP).

Materials and Methods: The observational study population comprises $35 \mathrm{MDD}$ and 14 BP subjects treated with intravenous ketamine.

Results: Blood pressure (RR) and heart rate (HR) values returned to baseline within 1.5hours post infusion with no sequelae for all study subjects. Six time points were analyzed for each infusion: 0', 15', 30', 45', 60' and 90' for RR and HR. After the infusion significant peaks in systolic $(\mathrm{p}=0.004)$ and diastolic $(\mathrm{p}=0.038) \mathrm{RR}$ were seen. In concomitant medication with selective serotonin reuptake inhibitors (SSRIs), higher RR peaks ( $\mathrm{p}=$ $0.020 ; p=0.048$ ) were seen as compared to other subjects. The decrease in HR was greater $(\mathrm{p}=0.02)$ in the absence of concomitant medication with mood stabilizers as compared to subjects receiving mood stabilizing medication accompanied by the observation of a greater decrease in diastolic RR among those taking mood stabilizers $(\mathrm{p}=0.009)$.

Limitations: The study may be underpowered due to the small sample size. The observations apply to an inhomogeneous TRD population in a single-site, pilot study, with no blinding and are limited to the acute administration.

Conclusion: The study demonstrates good safety and tolerability profile of intravenous ketamine as add-on intervention to current psychotropic medication in TRD, regardless of the MDD or BP type of mood disorders. The abatement of elevated RR and BP scores was observed in time with no sequelae nor harm. Still, cardiovascular risks appear to be more pronounced in subjects with comorbid arterial hypertension and diabetes mellitus.

Keywords: ketamine, treatment resistant depression, major depressive disorder, bipolar disorder, cardiovascular, safety, tolerability

\section{Introduction}

There is evidence for ketamine use in treatment resistant depression (TRD) for major depressive disorder (MDD) and bipolar disorder (BP). Several concerns arise regarding ketamine use with the safety and tolerability of the drug. ${ }^{1-4}$

One of the main concerns is the possibility of adverse events related with cardiovascular symptomatology. ${ }^{5}$ There is evidence of frequent cardiovascular symptoms, but safe in treatment resistant depression (TRD) in both major depressive disorder (TRD-MDD) and the depressive phase of bipolar disorder (TRD-BP). However, the data on cardiovascular safety in BP is limited to a few papers. $^{6,7}$ 
Since the very beginning of ketamine use in medicine, temporary cardiovascular stimulatory effects have been reported with ketamine, beginning abruptly after dosing for general anesthesia (at doses of $0.5-2 \mathrm{mg} / \mathrm{kg}$ intravenously), including an increase in arterial blood pressure (RR) and heart rate (HR). ${ }^{8}$ The indirect sympathomimetic effect dominates in physiological conditions, it is responsible for ketamine's direct cardio-depressant and negative inotropic effects, in which systemic release of catecholamines, inhibiting the 10th (vagal) cranial nerve and inhibiting norepinephrine and epinephrine reuptake at peripheral nerves and within the myocardium plays a significant role. ${ }^{9}$ Some evidence that ketamine may produce clinically non-significant RR and BP elevations with IV infusion of ketamine $(0.5 \mathrm{mg} / \mathrm{kg}$ over $40 \mathrm{~min}$.) in patients with MDD was associated with mean systolic RR and diastolic RR increase by approximately $3.2 \mathrm{mmHg}$ at peak, 0.5 hour into the infusions, and returned to baseline levels during post-infusion monitoring. ${ }^{10}$ Still, Wan et al reported high, transitory RR increases (peak increase of 19.6 (systolic)/13.4 (diastolic) $\mathrm{mmHg}$ based on 205 ketamine infusions). ${ }^{11}$ These cardiovascular effects may be confusing for the treatment of patients with TRD who have somatic comorbidities such as arterial hypertension and/or cardiovascular diseases. It seems important to study the cardiovascular effects of ketamine, given that patients with TRD are at amplified risk of cardiac morbidity. To our best knowledge this is the first study reporting the results for multiple ketamine administrations for bipolar disorder cohort.

We report herein the cardiovascular effects of ketamine adjunctive to an oral antidepressant/mood stabilizer, in patients with TRD. The purpose of this paper is to investigate the relationship between cardiovascular measures and psychometric outcomes in the course of intravenous ketamine treatment in treatment refractory inpatients with MDD and BP.

\section{Methods and Population}

This study includes post hoc data analysis obtained from the naturalistic observational protocol (NCT04226963) for ketamine use in mood disorders including safety, tolerability, and efficacy measures in adult individuals. The diagnosis of MDD or BP was established based on Diagnostic and Statistical Manual of Mental Disorders (DSM-5) criteria and Mini International Neuropsychiatric Interview (MINI). Treatment resistance was defined as therapeutic failure to respond to at least two lines of antidepressant interventions for the current major depressive episode. ${ }^{12,13}$ Study followed the same rater-per-patient rule for repeated psychometric measurements as Montgomery-Åsberg Depression Rating Scale (MADRS), Young Mania Rating Scale (YMRS) and Columbia-Suicide Severity Rating Scale (C-SSRS). The exclusion criteria included uncontrolled medical conditions, diagnosis of psychotic disorder, current substance use disorder, cognitive decline, pregnancy or breast feeding.

The study was carried out in accordance with the latest version of the Declaration of Helsinki. The studies involving human participants were reviewed and approved by the Independent Ethics Committee of the Medical University of Gdansk NKBBN/172/2017; 172-674/2019.

\section{Study Design: Ketamine Infusions}

The study followed an observational design with all patients continuing baseline standard-of-care medication. Patients received 8 ketamine infusions over 4 weeks. Ketamine was dosed at $0.5 \mathrm{mg} / \mathrm{kg}$ and diluted into $0.9 \%$ saline solution administered over 40 minutes. Safety monitoring was assessed by the study clinician before, during and post-infusion every 15 minutes up to 90 minutes postinfusion. Safety, including vital signs, mental status and adverse incidents, were monitored and recorded at 15 minute intervals. Psychometric assessment with MADRS and YMRS was performed before first, third, fifth and seventh infusion and one week after last infusion. The ECG was carried out before every second infusion and one week after the last ketamine infusion. All clinicians were board-certified psychiatrists, familiar with behavioral management of patients with marked mental status changes and prepared to treat any emergency behavioral situations. Additionally, an on-site clinician was available and evaluated the patient for potential behavioral risks, including suicidal ideation, after the end of each session. As a risk mitigation measure, guidance on BP monitoring on intranasal treatment days was provided to investigators (ie, no dosing if predose SBP $>140 \mathrm{mmHg}$ ( $>150$ for age $>65$ years) or DBP $>90 \mathrm{mmHg}$; dose interruption if postdose SBP $\geq 200 \mathrm{mmHg}$ ( $\geq 190$ for age $>65$ years) or DBP $\geq 110 \mathrm{mmHg}(\geq 100$ for age $>65$ years $)$ ); subjects with elevated BPs were referred to a specialist for evaluation and hypothetical treatment. Blood pressure and heart rate measurements were assessed after the patient had rested for at least $5 \mathrm{~min}$ and were measured supine, either with a certified, completely automated device at predose $(0 \mathrm{~min}$ utes), and at 15, 30, 45, 60, and 90 minutes. A subject was 
defined as a responder at a given time point if the percent improvement from baseline in MADRS total score was at least $50 \%$. A subject was defined as remitter at a given time point if the MADRS total score was $\leq 10$ points. ${ }^{14}$ The groups (remitters, responders, non-remitters) were determined at the end of the study, during follow-up, when final MADRS evaluation took place.

\section{Statistical Analysis}

The primary outcome of interest was change in SBP and DBP from pre-infusion to highest post-infusion measurement. The analysis was conducted using the IBM statistical software SPSS Statistics version 25.0. To determine the differences between responders, remitters and non-responders for sociodemographic variables and the occurrence of diseases and treatment, frequency analyses were carried out with Fisher's exact test. When assessing the statistical significance between dichotomous groups, the MannWhitney $U$-test was utilized. For within subject and group analyses the Kruskal-Wallis tests were conducted. $\alpha=0.05$ was adopted as the level of significance for the purposes of this analysis.

Due to the small sample size non-parametric tests were used and in inequities among groups analyzed were used for the analysis for discrete and continuous variables.

\section{Results}

The clinical and demographic characteristics of the study group are presented in Table 1.

Analysis of variance was performed for repeated measurements for HR and RR systolic and diastolic. Six time points were analyzed for each infusion: 0', 15', 30', 45', $60^{\prime}$ and $90^{\prime}$. Analyses were carried out for each measurement (infusion) separately checking the differences between the measurements according to the time scale. All infusions were well tolerated and there was no need for interruption of the infusion due to unstable vital sign values or psychomimetic side effects. None of the subjects required pharmacological intervention to treat elevated $R R$ or HR.

First, analyses were made for HR. Collective results for the analyses are presented in the Table 2.

A comparison was made in patients who received from the first to sixth infusion to evaluate if there was a development of tolerance or tachyphylaxis.

The analysis showed that for infusion 1 significant differences in HR were noted between the measurements made after 30' and 90' $(\mathrm{p}=0.030)$, the HR level after 90 minutes was significantly lower than after 30 minutes. For infusion 2, significant differences in the HR level occurred between the measurements after 30' and 60' $(\mathrm{p}=0.011)$ and $30^{\prime}$ and $90^{\prime}(\mathrm{p}=0.003)$. The HR level at $30^{\circ}$ was significantly higher than for later measurements. For infusion 3, significant differences in the level of HR occurred between the measurement at 30' and 90' $(\mathrm{p}=0.046)$. HR measurement at 30' was higher than at 90'. For infusion 5 the differences in the HR level were analogous to the previous ones, for the measurement after 30' the HR level was higher than for the measurement after $90^{\prime}(\mathrm{p}=$ 0.014). For infusion 6, the HR level measured at 30' was significantly higher than for the measurement at $60^{\prime}(\mathrm{p}=$ $0.017)$ and $90^{\circ}(p=0.001)$. Figure 1 presents the means for the analyzed measurements.

Similar analyses were performed for systolic RR.

A comparison was made in patients who received from first to sixth infusion to evaluate if there was a development of tolerance or adaptation.

The results are presented in Table 3 and demonstrate that a significant increase was shown in systolic RR after $30^{\prime}(\mathrm{p}=0.006)$ and $45^{\prime}(\mathrm{p}=0.028)$ as compared to the $0^{\prime}$ measurement for infusion 1. Measurement at 15 ' was significantly higher than that made at $90^{\prime}(\mathrm{p}=0.001)$. The systolic RR measured at 30' was significantly higher than the measurement for 60' $(\mathrm{p}<0.001)$ and 90' (p $<0.001)$. Also, the measurement made at $45^{\prime}$ was significantly higher than that made at $60^{\prime}(\mathrm{p}=0.002)$ and $90^{\prime}(\mathrm{p}$ $<0.001)$. For infusion 2, analysis of the results showed that the measurement at $90^{\prime}$ 'was significantly lower than for the measurement at $30^{\prime}(p=0.016)$ and $45^{\prime}(p=0.038)$. For infusion 3, the systolic RR at 30' was significantly higher than for $0^{\prime}(p=0.010), 60^{\prime}(p=0.008)$ and $90^{\prime}(p=$ $0.001)$. The systolic $R R$ at $45^{\prime}$ was significantly higher than for $60^{\prime}(p=0.002)$ and $90^{\prime}(p<0.001)$. For infusion 4 , the level of systolic RR at 90' was significantly lower than for the measurements at $0^{\prime}(p=0.024), 30^{\prime}(p=0.001)$, $45^{\prime}(p=0.001)$ and 60' $(p=0.008)$. The measurement of systolic RR at 30' was significantly higher than for the measurement at $15^{\prime}(\mathrm{p}=0.014)$ and 60' $(\mathrm{p}=0.036)$, and at $45^{\prime}$ was higher than at $60^{\prime}(\mathrm{p}=0.011)$. For infusion 5 , the systolic RR level measured at 30' was significantly higher than at $0^{\prime}(\mathrm{p}=0.005), 60^{\prime}(\mathrm{p}=0.009)$ and $90^{\prime}(\mathrm{p}<0.001)$. The measurement at 90' was significantly lower than the measurement at $45^{\prime}(\mathrm{p}<0.001)$, as was the measurement of $60^{\prime}$ lower than at $45^{\prime}(\mathrm{p}=0.001)$. Detailed analysis of the results for infusion 6 showed that the measurement of systolic RR at 30' was significantly higher than for the 
Table I Clinical and Demographic Characteristic of the Study Group

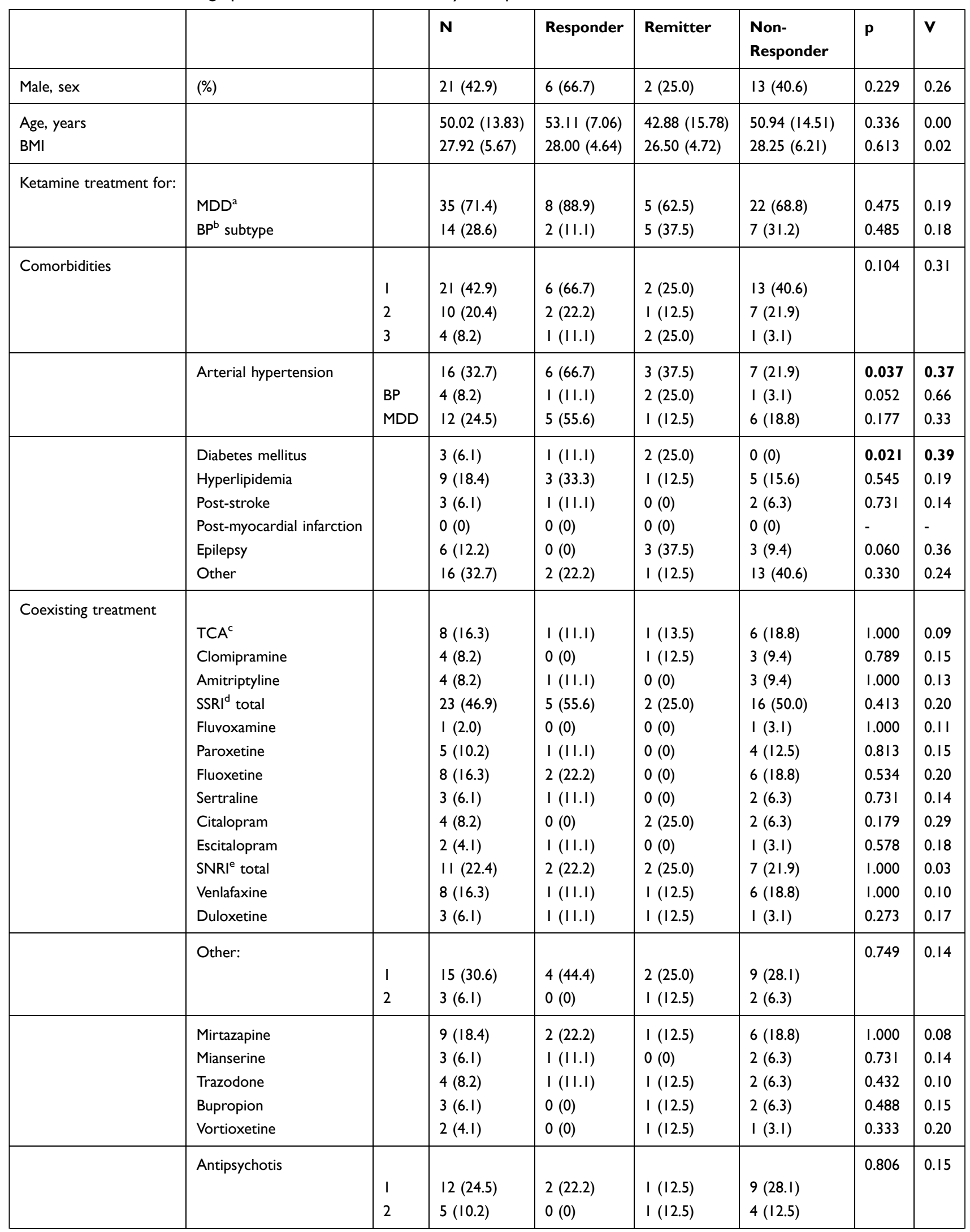

(Continued) 
Table I (Continued).



Notes: ${ }^{a} \mathrm{MDD}$ - major depressive disorder. ${ }^{\mathrm{b}} \mathrm{BP}$ - bipolar disorder. ${ }^{\mathrm{C}} \mathrm{TCA}$ - other than mentioned tricyclic antidepressants. ${ }^{\mathrm{d}} \mathrm{SSRI}$ - selective serotonin reuptake inhibitors.



Table 2 Analysis of Variance with Repeated Measurement for HR

\begin{tabular}{|l|l|l|l|l|}
\hline & $\boldsymbol{F}$ & df & $\boldsymbol{p}$ & $\boldsymbol{\eta}_{\mathbf{p}}$ \\
\hline Infusion I & 3.02 & 3.263 & 0.028 & 0.06 \\
Infusion 2 & 4.68 & 2.329 & 0.008 & 0.09 \\
Infusion 3 & 3.02 & 3.01 & 0.032 & 0.06 \\
Infusion 4 & 2.51 & 2.345 & 0.077 & 0.05 \\
Infusion 5 & 3.76 & 3.224 & 0.01 & 0.07 \\
Infusion 6 & 3.77 & 3.143 & 0.011 & 0.07 \\
Infusion 7 & 1.98 & 3.5 & 0.109 & 0.05 \\
Infusion 8 & 4.02 & 3.243 & 0.007 & 0.09 \\
\hline
\end{tabular}

measurement at 90' $(\mathrm{p}=0.003)$, and the measurement at $45^{\prime}$ was significantly higher than that at $60^{\prime}(\mathrm{p}=0.021)$ and $90^{\prime}(\mathrm{p}=0.003)$. For infusion 7 , the measurement at 15 ' was significantly higher than at 0 ' $(\mathrm{p}=0.016)$, 60'
Table 3 Analysis of Variance with Repeated Measurements for Systolic RR

\begin{tabular}{|l|l|l|l|l|}
\hline & $\boldsymbol{F}$ & $\mathbf{d f}$ & $\boldsymbol{p}$ & $\boldsymbol{\eta}_{\mathbf{p}}$ \\
\hline Infusion I & 11.010 & 3.342 & $<0.00 \mathrm{I}$ & 0.19 \\
Infusion 2 & 4.70 & 2.660 & 0.005 & 0.09 \\
Infusion 3 & 7.60 & 3.170 & $<0.00 \mathrm{I}$ & 0.14 \\
Infusion 4 & 7.56 & 2.807 & $<0.00 \mathrm{I}$ & 0.14 \\
Infusion 5 & 6.14 & 2.842 & $0.00 \mathrm{I}$ & 0.12 \\
Infusion 6 & 6.03 & 2.162 & 0.003 & $0.1 \mathrm{I}$ \\
Infusion 7 & 13.74 & 2.844 & $<0.00 \mathrm{I}$ & 0.25 \\
Infusion 8 & 5.36 & 2.064 & 0.006 & 0.12 \\
\hline
\end{tabular}

( $p<0.001)$ and 90' ( $<<0.001)$. Analogous differences occur for the measurement made at 30 ' $(\mathrm{p}<0.001)$. The systolic RR was significantly higher for the measurement at $45^{\prime}$ than for $60^{\prime}(\mathrm{p}=0.013)$ and $90^{\prime}(\mathrm{p}<0.001)$. The

$$
\llbracket 0^{\prime} \sqsubset 15^{\prime}=30^{\prime} \square 45^{\prime} \square 60^{\prime} \square 90^{\prime}
$$

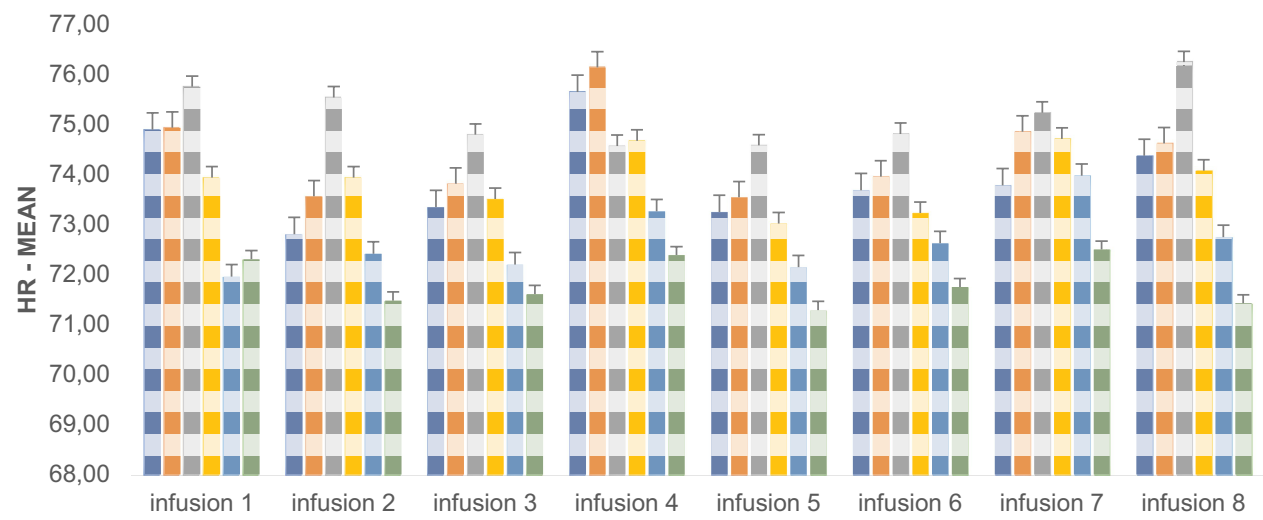

Figure I Mean HR fluctuations over time. 
measurement at 90' was significantly lower than the measurement of systolic RR between 15' and 60' ( $\mathrm{p} \leq 0.001$ ). For the last infusion, the systolic RR at 30' was significantly higher than that at 60' $(\mathrm{p}=0.001)$ and $90^{\prime}(\mathrm{p}$ $<0.001)$. The measurement of $15^{\prime}$ was higher than that of $90^{\prime}(\mathrm{p}=0.001)$. The measurement at 90' was significantly lower than the other measurements, except $0^{\prime}(\mathrm{p} \leq 0.011)$. Systolic RR in 60' was lower than in $45^{\prime}(\mathrm{p}=0.001)$. Figure 2 presents the means for the analyzed measurements.

Similar analyses were also carried out for diastolic RR which we present in Table 4.

The analysis presented in Table 4 showed significant differences between measurements within all infusions. Detailed analysis of the results showed that for infusion 1, the measurement of diastolic RR at 90' was significantly lower than that made at $30^{\prime}(\mathrm{p}=0.016)$ and $45^{\prime}(\mathrm{p}=0.009)$. For infusion 2, significant differences occurred between the measurement of diastolic RR at 30' and 90' $(\mathrm{p}=0.007)$, in later measurement, diastolic RR was at a lower level. For infusion 3, the diastolic RR at 90' was significantly lower than for the measurement made at 30' $(p=0.004), 45^{\prime}(p=$ $0.003)$ and $60 '(p=0.006)$. For infusion 4 , the analysis showed that the diastolic RR at 0 ' was significantly lower than at $45^{\prime}(p=0.018)$. In addition, the RR measurement at 90 ' was significantly lower than the other measurements (except 0'; $\mathrm{p} \leq 0.004$ ). Diastolic RR at 45' was higher than at 60' $(\mathrm{p}=0.006)$. Detailed analysis for infusion 5 showed that the diastolic RR level at 90' was significantly lower than measurements made between $15^{\prime}$ and $45^{\prime}(\mathrm{p} \leq 0.008)$. The measurement of 45 ' was significantly higher than the measurement at $0^{\prime}(p=0.042)$ and $60^{\prime}(p=0.028)$. For
Table 4 Analysis of Variance with Repeated Measurements for Diastolic RR

\begin{tabular}{|l|l|l|l|l|}
\hline & $\boldsymbol{F}$ & $\mathbf{d f}$ & $\boldsymbol{p}$ & $\boldsymbol{\eta}_{\mathbf{p}}^{\mathbf{2}}$ \\
\hline Infusion I & 3.98 & 3.467 & 0.006 & 0.08 \\
Infusion 2 & 3.83 & 2.16 & 0.022 & 0.08 \\
Infusion 3 & 4.88 & 2.742 & 0.004 & 0.09 \\
Infusion 4 & 9.51 & 3.623 & $<0.001$ & 0.17 \\
Infusion 5 & 6.63 & 3.719 & $<0.001$ & 0.12 \\
Infusion 6 & 7.89 & 3.786 & $<0.001$ & 0.14 \\
Infusion 7 & 10.12 & 3.684 & $<0.001$ & 0.20 \\
Infusion 8 & 6.90 & 3.050 & $<0.001$ & 0.14 \\
\hline
\end{tabular}

infusion 6, the diastolic RR at 0 ' was significantly lower than at $15^{\prime}(\mathrm{p}=0.020)$ and $30^{\prime}(\mathrm{p}=0.012)$. The measurement at 90' was significantly lower than the measurements at $15^{\prime}(p=0.005), 30^{\prime}(p=0.001)$ and $45^{\prime}(p=0.003)$. For infusion 7 , the RR at 30' was significantly higher than at 0 ' $(\mathrm{p}=0.013), 60^{\prime}(\mathrm{p}=0.001)$ and $90^{\prime}(\mathrm{p}<0.001)$. The measurement at $15^{\prime}$ was significantly higher than at $60^{\prime}$ (p $=0.042$ ). The measurement at $45^{\prime}$ ' was significantly higher than at 60' $(\mathrm{p}=0.009)$ and $90^{\prime}(\mathrm{p}=0.005)$. For the last infusion, the diastolic RR at 30' was significantly higher than that at $0^{\prime}(p=0.004), 60^{\prime}(p=0.009)$ and 90' (p $<0.001$ ). The measurement at $45^{\prime}$ ' was significantly higher than that at $60^{\prime}(p=0.045)$ and $90^{\prime}(p=0.002)$, and the measurement at $60^{\prime}$ higher than from $90^{\prime}(p=0.003)$. Figure 3 presents the means for the analyzed measurements.

\section{Differences by Groups}

Analyses were performed for different clinical groups. The analyses compared measurements in patients with and without essential hypertension, patients who were treated

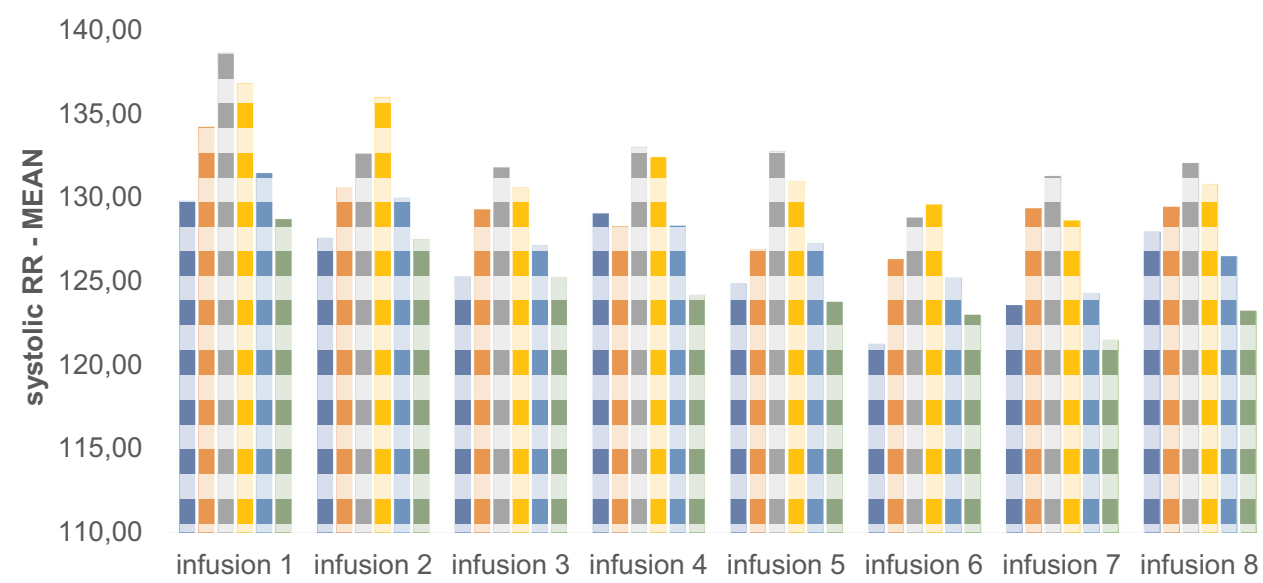

Figure 2 Mean RR changes over time in individual measurements (infusions). 


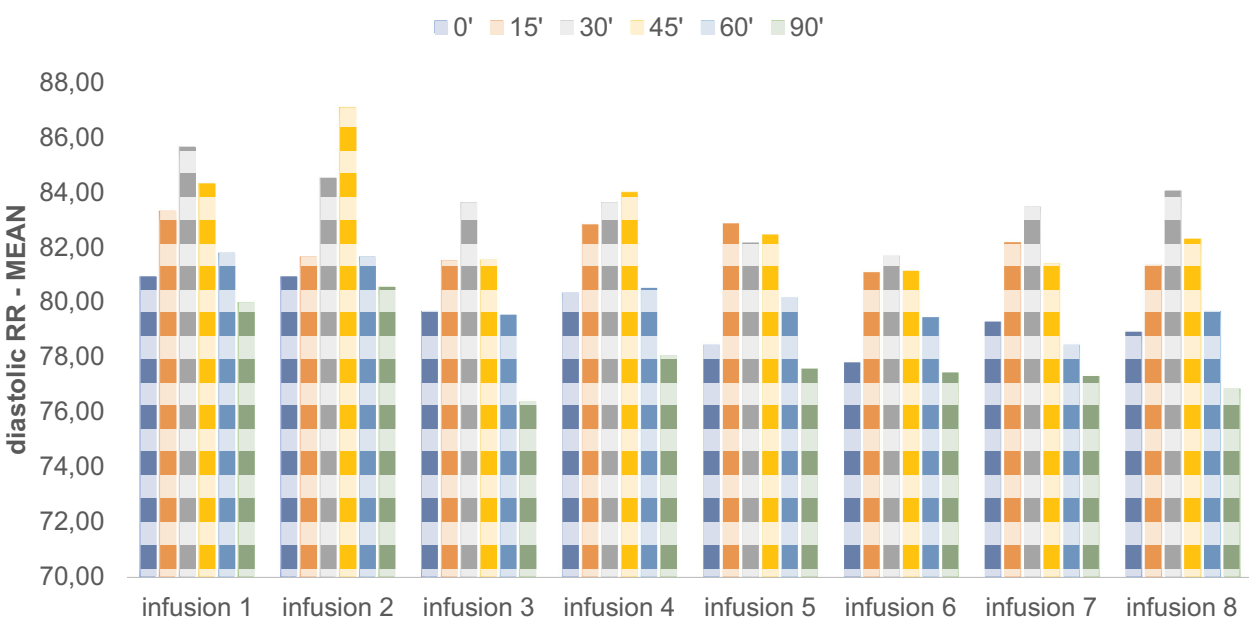

Figure 3 Mean HR changes over time in individual measurements (infusions).

for TRD-MDD and TRD-BP, patients treated with different classes of psychopharmacological agents are presented in Table 5.

Comparison of people suffering from and not suffering from arterial hypertension (HA) in terms of the mediumterm rate of change in $\mathrm{HR}$ and $\mathrm{BP}$ showed that among people with HA, there is a higher increase in systolic RR after infusion 2 than among those who do not have HA. An analogous situation occurred for diastolic RR after 1 infusion - a higher increase in diastolic RR is observed among people with HA compared to those not suffering from HA.

Comparison of $\mathrm{BP}$ and TRD in terms of mediumterm $\mathrm{HR}$ and $\mathrm{BP}$ rate change showed one significant difference between TRD and BP. In the BP group for diastolic RR for infusion 8 a higher decrease in $R R$ is observed than in the TRD group. For the remaining measurements, the differences between the groups turned out to be insignificant.

The analysis comparing different classes of psychopharmacological agents to $\mathrm{RR}$ and $\mathrm{HR}$ changes showed that for people taking selective serotonin reuptake inhibitors (SSRIs), the level of systolic RR change after the 3rd infusion is higher than for people who do not take these drugs. In the group of people not taking these drugs, the decrease in systolic RR after the 8th infusion is greater than among those taking SSRIs.

Among those taking antipsychotic drugs, the HR fall after the 4th infusion is greater than among those who do not take these drugs. The decrease in diastolic RR after 1 infusion among patients after antipsychotic drugs is greater than in the group that does not take such drugs.
Among those not taking mood stabilizers, the decrease in HR after the 2nd infusion is greater than in the group of people taking this type of medication. In addition, a greater decrease in diastolic RR after the 8th infusion is visible among those taking mood stabilizers.

\section{Discussion}

This research demonstrates the transient phenomenon of elevation of BP and RR related to ketamine infusion with good safety and tolerability profile of cardiovascular adverse drug reactions with ketamine as an add-on treatment to current psychotropic medication in TRD. The abatement of both, BP and HR, was demonstrated at the time of the treatment with no sequelae. Our analysis showed significant differences for cardiovascular scores before and after infusion in one measurement. Both BP and HR scores after infusion were significantly higher than before infusion for each of the 8 measurements. The effect strength for the differences was large. Which contributes to other data on ketamine IV studies in BP, as it is estimated that no more than $0.7 \%$ of the studies address BP in the population. ${ }^{15}$

When analyzing the different subgroups, it is apparent that hypertensive patients would have statistically significant increases in systolic and diastolic blood pressure than people without HA. However, these differences resolve at the end of monitoring. This may suggest that patients with essential HA do not need to be excluded from receiving ketamine infusions if their blood pressure is well controlled with antihypertensive agents. There were no differences between $H R / R R$ changes with regards to diagnosis, but psychotropic medication can be of importance. SSRIs, 
Table 5 Statistical Comparison Between Groups

\begin{tabular}{|c|c|c|c|c|c|c|c|c|c|c|c|c|}
\hline & & \multicolumn{4}{|c|}{ Non-HA $(n=33)$} & \multicolumn{4}{|c|}{ HA $(n=16)$} & \multirow[t]{2}{*}{$\mathbf{z}$} & \multirow[t]{2}{*}{$\mathbf{p}$} & \multirow[t]{2}{*}{$\mathbf{r}$} \\
\hline & & $\mathbf{M}$ & SD & Me & IQR & M & SD & Me & IQR & & & \\
\hline \multirow[t]{8}{*}{$H R$} & Inf. I & -1.24 & 9.30 & -1.69 & 9.92 & -5.60 & 14.88 & -0.72 & 13.64 & -0.17 & 0.865 & -0.02 \\
\hline & $\operatorname{lnf} 2$ & -1.65 & 8.27 & -1.39 & 6.64 & -0.67 & 7.15 & -2.15 & 9.66 & -0.31 & 0.759 & -0.04 \\
\hline & $\operatorname{lnf} 3$ & -1.75 & 8.91 & -1.00 & 11.81 & -1.44 & 9.37 & 0.02 & 11.20 & -0.09 & 0.932 & -0.01 \\
\hline & $\operatorname{lnf} 4$ & -1.95 & 11.07 & 0.00 & 6.73 & -4.75 & 10.27 & -1.29 & 14.54 & -0.80 & 0.424 & -0.11 \\
\hline & $\operatorname{lnf} 5$ & -4.08 & 8.17 & -2.15 & 11.47 & 1.95 & 10.54 & 0.00 & 11.62 & -1.65 & 0.099 & -0.24 \\
\hline & $\operatorname{lnf} 6$ & -2.08 & 9.42 & -1.40 & 9.77 & -1.89 & 8.17 & -2.30 & 11.04 & -0.14 & 0.887 & -0.02 \\
\hline & $\operatorname{lnf} 7$ & -1.94 & 10.57 & -2.74 & 13.34 & 0.72 & 7.83 & 0.00 & 12.97 & -1.12 & 0.262 & -0.16 \\
\hline & $\operatorname{lnf} 8$ & -3.57 & 13.02 & -2.74 & 9.42 & -0.85 & 10.46 & -1.67 & 10.02 & -0.57 & 0.566 & -0.08 \\
\hline \multirow[t]{8}{*}{ RR systolic } & $\inf I$ & -0.84 & 6.78 & 0.00 & 7.45 & 0.77 & 14.32 & 0.00 & 11.69 & -0.32 & 0.749 & -0.05 \\
\hline & $\inf 2$ & -2.21 & 6.68 & -0.83 & 7.79 & 4.96 & 9.97 & 7.14 & 10.17 & -2.88 & 0.004 & -0.41 \\
\hline & $\inf 3$ & -0.37 & 8.53 & 0.00 & 11.78 & 1.75 & 10.20 & 0.37 & 4.56 & -0.70 & $0.48 I$ & -0.10 \\
\hline & $\inf 4$ & -3.88 & 7.53 & -1.64 & 8.19 & -2.28 & 7.31 & -3.32 & 12.39 & -0.26 & 0.798 & -0.04 \\
\hline & $\inf 5$ & -0.27 & 9.83 & -1.61 & 6.60 & -0.10 & 8.41 & 0.00 & 10.26 & -0.81 & 0.418 & -0.12 \\
\hline & $\inf 6$ & -0.37 & 6.54 & 0.00 & 8.69 & 57.51 & 227.25 & 0.00 & 6.97 & -0.31 & 0.759 & -0.04 \\
\hline & $\inf 7$ & -1.15 & 7.94 & 0.00 & 9.77 & $-0.8 \mathrm{I}$ & 12.04 & 0.00 & 12.50 & -0.12 & 0.904 & -0.02 \\
\hline & $\inf 8$ & -2.78 & 11.79 & -3.82 & 12.85 & -1.68 & 6.50 & 0.00 & 7.12 & -0.75 & 0.454 & -0.11 \\
\hline \multirow[t]{10}{*}{ RR diastolic } & $\inf I$ & -2.90 & 10.01 & -2.78 & 10.04 & 6.12 & 14.69 & 2.63 & 16.69 & -2.07 & 0.038 & -0.30 \\
\hline & $\inf 2$ & -1.89 & 7.30 & 0.00 & 6.05 & 4.42 & 12.00 & 4.22 & 17.34 & -1.70 & 0.089 & -0.24 \\
\hline & $\inf 3$ & -2.15 & 13.75 & 0.00 & 15.69 & -5.08 & 18.34 & -0.63 & 20.99 & -0.08 & 0.940 & -0.01 \\
\hline & $\inf 4$ & -0.53 & 10.43 & 0.00 & 14.47 & -4.56 & 10.34 & -0.63 & $|5.6|$ & -0.90 & 0.368 & -0.13 \\
\hline & $\inf 5$ & -1.00 & 9.96 & -2.55 & 10.63 & 1.32 & 12.53 & 0.00 & 14.12 & -0.75 & 0.456 & -0.11 \\
\hline & $\inf 6$ & -0.82 & 10.16 & -0.63 & 8.38 & 2.23 & 7.22 & 0.00 & 8.34 & -1.27 & 0.204 & -0.18 \\
\hline & $\inf 7$ & -1.67 & II.48 & -2.44 & 8.83 & -2.13 & 6.10 & 0.00 & 4.15 & -0.68 & 0.494 & -0.10 \\
\hline & $\inf 8$ & $-|.5|$ & 9.78 & 0.00 & 13.13 & -2.61 & 8.75 & -1.25 & 10.77 & -0.38 & 0.703 & -0.05 \\
\hline & & \multicolumn{4}{|c|}{$\operatorname{TRD}(n=36)$} & \multicolumn{4}{|c|}{$B D(n=13)$} & & & \\
\hline & & M & SD & $\mathrm{Me}$ & IQR & M & SD & $\mathrm{Me}$ & IQR & $z$ & $P$ & $r$ \\
\hline \multirow[t]{8}{*}{$H R$} & $\inf I$ & -2.80 & 12.68 & -1.57 & 12.95 & -2.28 & 7.43 & -1.61 & 6.16 & -0.17 & 0.865 & -0.02 \\
\hline & $\inf 2$ & -2.05 & 7.84 & -2.22 & 6.80 & 0.63 & 7.86 & 1.37 & 9.00 & -1.43 & 0.154 & -0.20 \\
\hline & $\inf 3$ & -2.39 & 9.42 & -1.15 & 11.96 & 0.40 & 7.53 & 1.30 & 8.11 & $-0.7 \mid$ & 0.476 & -0.10 \\
\hline & $\inf 4$ & -2.85 & 11.66 & 0.00 & 6.31 & -2.89 & 8.30 & -2.60 & 10.18 & -0.84 & 0.402 & -0.12 \\
\hline & $\inf 5$ & -2.06 & 10.09 & -1.39 & 11.18 & -2.10 & 7.46 & -2.82 & 8.76 & -0.05 & 0.963 & -0.01 \\
\hline & $\inf 6$ & -2.48 & 9.36 & -1.47 & 9.83 & -0.77 & 7.88 & 0.00 & 9.57 & -0.46 & 0.643 & -0.07 \\
\hline & $\inf 7$ & -1.45 & 10.69 & -2.18 & 11.78 & -0.07 & 7.09 & -0.68 & 11.69 & -0.54 & 0.587 & -0.08 \\
\hline & $\inf 8$ & -3.92 & 13.65 & -2.33 & 12.98 & -0.09 & 8.14 & -2.70 & 7.53 & -0.62 & 0.538 & -0.09 \\
\hline \multirow[t]{8}{*}{ RR systolic } & $\inf I$ & 0.17 & 9.89 & 0.00 & 7.37 & -1.68 & 9.66 & -1.43 & $|1.6|$ & -0.44 & 0.659 & -0.06 \\
\hline & $\inf 2$ & 0.47 & 8.96 & 0.00 & 12.88 & -0.60 & 7.54 & 0.00 & 10.67 & -0.14 & 0.889 & -0.02 \\
\hline & $\inf 3$ & 1.41 & 9.48 & 0.00 & 7.41 & -2.68 & 7.26 & -4.14 & 9.87 & -1.62 & 0.105 & -0.23 \\
\hline & $\inf 4$ & -2.59 & 6.32 & -2.42 & 8.28 & -5.47 & 9.85 & -4.00 & 10.93 & -0.78 & 0.434 & -0.11 \\
\hline & $\inf 5$ & -0.03 & 9.50 & 0.00 & 5.73 & $-0.7 \mid$ & 9.04 & -1.56 & 12.17 & -0.04 & 0.972 & -0.01 \\
\hline & $\inf 6$ & 25.38 & 153.88 & 0.00 & 7.88 & 1.54 & 10.04 & 0.00 & 7.95 & -0.53 & 0.593 & -0.08 \\
\hline & $\inf 7$ & -0.35 & 9.48 & 0.00 & 11.08 & -2.75 & 9.21 & -1.90 & 12.82 & -0.56 & 0.577 & -0.08 \\
\hline & $\inf 8$ & 0.39 & 7.46 & 0.00 & 10.01 & -8.75 & 13.23 & -7.69 & 9.96 & -2.59 & 0.010 & -0.37 \\
\hline \multirow[t]{4}{*}{ RR diastolic } & $\inf I$ & 1.08 & 12.43 & 0.00 & 10.15 & -2.84 & 12.11 & 0.00 & 14.42 & -0.35 & 0.725 & -0.05 \\
\hline & $\inf 2$ & -0.43 & 8.58 & 0.00 & 8.21 & 1.96 & 11.83 & 0.00 & 18.13 & -0.78 & 0.435 & -0.11 \\
\hline & $\inf 3$ & -2.19 & 16.52 & 0.00 & 19.08 & -5.63 & 11.27 & -9.18 & 14.39 & -1.05 & 0.292 & -0.15 \\
\hline & $\inf 4$ & -0.7 I & 9.95 & 0.00 & 11.57 & -5.02 & $11.6 \mathrm{I}$ & -6.25 & 15.66 & $-I . I I$ & 0.269 & -0.16 \\
\hline
\end{tabular}

(Continued) 
Table 5 (Continued).

\begin{tabular}{|c|c|c|c|c|c|c|c|c|c|c|c|c|}
\hline & & \multicolumn{4}{|c|}{ Non-HA $(n=33)$} & \multicolumn{4}{|c|}{ HA $(n=16)$} & \multirow[t]{2}{*}{$\mathbf{Z}$} & \multirow[t]{2}{*}{$\mathbf{p}$} & \multirow[t]{2}{*}{$\mathbf{r}$} \\
\hline & & $\mathbf{M}$ & SD & Me & IQR & $\mathbf{M}$ & SD & Me & IQR & & & \\
\hline & $\inf 5$ & -0.17 & 10.21 & 0.00 & 13.10 & -0.40 & 12.72 & 0.00 & 9.05 & -0.38 & 0.701 & -0.05 \\
\hline & $\inf 6$ & 0.91 & 9.84 & 0.00 & 12.62 & -1.73 & 7.76 & 0.00 & 3.54 & -0.14 & 0.888 & -0.02 \\
\hline & $\inf 7$ & -1.06 & 9.95 & 0.00 & 5.99 & -3.72 & 10.07 & -2.68 & 12.19 & -1.23 & 0.218 & -0.18 \\
\hline & $\inf 8$ & -0.19 & 8.24 & 0.00 & 8.89 & -5.54 & 11.00 & -8.70 & 18.29 & -1.76 & 0.079 & -0.25 \\
\hline & & \multicolumn{4}{|c|}{ Non-SSRI $(n=26)$} & \multicolumn{4}{|c|}{ SSRI (n = 23) } & & & \\
\hline & & M & SD & $\mathrm{Me}$ & IQR & M & SD & $\mathrm{Me}$ & IQR & Z & $\mathrm{P}$ & $r$ \\
\hline \multirow[t]{8}{*}{$H R$} & $\inf I$ & -1.36 & 8.40 & -0.81 & 7.12 & -4.13 & 14.20 & -1.69 & 14.45 & -0.06 & 0.952 & -0.01 \\
\hline & $\inf 2$ & 0.67 & 7.75 & -1.18 & 9.68 & -3.49 & 7.53 & -2.22 & 9.45 & -1.21 & 0.227 & -0.17 \\
\hline & $\inf 3$ & -1.89 & 8.45 & 0.65 & 12.94 & -1.37 & 9.71 & -1.56 & 13.39 & -0.01 & 0.992 & 0.00 \\
\hline & $\inf 4$ & -1.64 & 7.31 & -0.60 & 4.12 & -4.24 & 13.76 & 0.00 & 13.29 & 0.00 & 1.000 & 0.00 \\
\hline & $\inf 5$ & -1.98 & 7.43 & -1.39 & 5.79 & -2.18 & 11.28 & -1.45 & 13.63 & -0.52 & 0.606 & -0.07 \\
\hline & $\inf 6$ & -2.00 & 7.26 & -1.47 & 8.81 & -2.04 & 10.63 & -1.41 & 17.46 & -0.10 & 0.918 & -0.01 \\
\hline & $\inf 7$ & $-0.4 I$ & 9.18 & 0.00 & 8.53 & -1.64 & 10.39 & -2.78 & 13.20 & -0.73 & 0.465 & -0.10 \\
\hline & $\inf 8$ & 0.06 & 9.64 & 0.00 & 10.33 & -6.24 & 14.37 & -2.88 & 10.74 & -1.47 & 0.141 & -0.21 \\
\hline \multirow[t]{8}{*}{ RR systolic } & $\inf I$ & -0.43 & 7.67 & 0.00 & 5.72 & -0.19 & 11.88 & -0.79 & 11.38 & -0.36 & 0.718 & -0.05 \\
\hline & $\inf 2$ & -0.12 & 9.76 & 0.00 & 12.69 & 0.52 & 7.17 & -0.72 & 11.69 & -0.04 & 0.967 & -0.01 \\
\hline & $\inf 3$ & -3.09 & 8.07 & 0.00 & 14.85 & 4.18 & 8.70 & 2.33 & 9.99 & -2.33 & 0.020 & -0.33 \\
\hline & $\inf 4$ & $-4.1 I$ & 7.89 & -3.60 & 7.94 & -2.50 & 6.93 & -1.64 & 10.62 & $-0.4 I$ & 0.681 & -0.06 \\
\hline & $\inf 5$ & -0.09 & 9.72 & 0.00 & 8.64 & -0.35 & 9.01 & 0.00 & 6.19 & -0.29 & 0.772 & -0.04 \\
\hline & $\inf 6$ & 35.75 & 182.13 & 0.00 & 9.94 & 0.64 & 6.29 & 0.00 & 8.20 & -0.44 & 0.657 & -0.06 \\
\hline & $\inf 7$ & -2.49 & 8.52 & 0.00 & $|3.6|$ & 0.28 & 10.07 & 0.00 & 9.18 & -0.69 & 0.488 & -0.10 \\
\hline & $\inf 8$ & -5.03 & 12.39 & -4.00 & 9.01 & 0.69 & 6.20 & 0.00 & 12.16 & -1.97 & 0.048 & -0.28 \\
\hline \multirow[t]{10}{*}{ RR diastolic } & $\inf I$ & -1.54 & 13.24 & -1.39 & 16.18 & 1.83 & 11.27 & 0.00 & 7.95 & -0.74 & 0.458 & -0.11 \\
\hline & $\inf 2$ & 0.58 & 10.39 & 0.00 & $|3.7|$ & -0.18 & 8.64 & 0.00 & 7.08 & -0.45 & 0.656 & -0.06 \\
\hline & $\inf 3$ & -3.48 & 13.06 & -2.25 & 18.24 & -2.67 & 17.73 & 0.00 & 16.88 & -0.40 & 0.688 & -0.06 \\
\hline & $\inf 4$ & -2.19 & 9.88 & 0.00 & II.07 & -1.47 & 11.31 & 0.00 & 17.91 & -0.17 & 0.864 & -0.02 \\
\hline & $\inf 5$ & 1.92 & 10.61 & 0.00 & 12.45 & -2.56 & 10.76 & -3.85 & 10.24 & -1.79 & 0.073 & -0.26 \\
\hline & $\inf 6$ & 0.62 & 10.99 & -1.47 & 8.88 & -0.27 & 7.30 & 0.00 & 8.55 & -0.55 & 0.581 & -0.08 \\
\hline & $\inf 7$ & -1.01 & 12.59 & -0.62 & 9.02 & -2.56 & 6.94 & -2.38 & 5.99 & -0.30 & $0.76 \mathrm{I}$ & -0.04 \\
\hline & $\inf 8$ & -2.07 & 9.60 & 0.00 & 11.69 & -1.58 & 9.37 & -1.25 & 9.08 & -0.06 & 0.950 & -0.01 \\
\hline & & \multicolumn{4}{|c|}{ Non-SNRI $(n=38)$} & \multicolumn{4}{|c|}{ SNRI $(n=I I)$} & & & \\
\hline & & $M$ & SD & $\mathrm{Me}$ & IQR & $M$ & SD & $\mathrm{Me}$ & IQR & Z & $\mathrm{P}$ & $r$ \\
\hline \multirow[t]{8}{*}{ HR } & $\inf I$ & -4.00 & 11.75 & -1.69 & 12.87 & 1.98 & 9.38 & 0.00 & 5.56 & -1.17 & 0.240 & -0.17 \\
\hline & $\inf 2$ & -2.28 & 6.96 & -2.12 & 6.70 & 2.31 & 10.20 & 2.22 & $|2.8|$ & -1.30 & 0.195 & -0.19 \\
\hline & $\inf 3$ & -1.44 & 9.13 & -1.21 & 11.83 & -2.34 & 8.75 & 0.00 & 11.81 & -0.04 & $0.97 I$ & -0.01 \\
\hline & $\inf 4$ & -3.37 & 12.03 & -0.61 & 13.06 & -1.11 & 4.38 & 0.00 & 3.80 & -0.08 & 0.933 & -0.01 \\
\hline & $\inf 5$ & -1.77 & 10.15 & -1.39 & 11.16 & -3.24 & 5.75 & -2.08 & 9.53 & -0.37 & 0.713 & -0.05 \\
\hline & $\inf 6$ & -1.07 & 9.48 & -0.69 & 9.75 & -5.64 & 5.40 & -5.36 & 6.33 & -1.60 & 0.110 & -0.23 \\
\hline & $\inf 7$ & -1.63 & 9.90 & -2.18 & 11.03 & 1.37 & 9.19 & 2.46 & 10.25 & -1.27 & 0.206 & -0.18 \\
\hline & $\inf 8$ & -4.47 & 12.28 & -2.78 & 8.73 & 2.78 & 10.69 & 3.20 & 17.44 & -1.55 & 0.121 & -0.22 \\
\hline \multirow[t]{4}{*}{ RR systolic } & $\inf I$ & -0.95 & 9.68 & -1.48 & 10.83 & 1.86 & 10.23 & 0.00 & 4.67 & -1.43 & 0.154 & -0.20 \\
\hline & $\inf 2$ & -0.53 & 7.98 & -0.36 & 12.80 & 2.90 & 10.40 & 2.05 & 10.09 & -0.94 & 0.347 & -0.13 \\
\hline & $\inf 3$ & 0.71 & 9.57 & 0.00 & 11.15 & -1.03 & 7.25 & 0.00 & 8.30 & -0.43 & 0.666 & -0.06 \\
\hline & $\inf 4$ & -3.97 & 7.49 & -3.32 & 9.27 & -1.24 & 7.10 & 0.00 & II.67 & -1.12 & 0.265 & -0.16 \\
\hline
\end{tabular}

(Continued) 
Table 5 (Continued).

\begin{tabular}{|c|c|c|c|c|c|c|c|c|c|c|c|c|}
\hline & & \multicolumn{4}{|c|}{ Non-HA $(n=33)$} & \multicolumn{4}{|c|}{ HA $(n=16)$} & \multirow[t]{2}{*}{$\mathbf{Z}$} & \multirow[t]{2}{*}{$\mathbf{p}$} & \multirow[t]{2}{*}{$\mathbf{r}$} \\
\hline & & $\mathbf{M}$ & SD & Me & IQR & $\mathbf{M}$ & SD & Me & IQR & & & \\
\hline & $\inf 5$ & -1.13 & 8.54 & -0.77 & 6.02 & 3.26 & 11.56 & 0.00 & 12.98 & -0.66 & 0.509 & -0.09 \\
\hline & wlew 6 & 23.17 & 147.73 & 0.00 & 7.26 & 2.80 & 10.06 & 1.92 & 11.09 & -0.85 & 0.395 & -0.12 \\
\hline & $\inf 7$ & -1.84 & 9.61 & 0.00 & 10.61 & 2.36 & 7.82 & 2.84 & 6.27 & -1.64 & 0.102 & -0.23 \\
\hline & $\inf 8$ & -0.40 & 8.13 & 0.00 & 13.01 & -8.98 & 14.14 & -4.55 & 11.79 & -1.91 & 0.056 & -0.27 \\
\hline \multirow[t]{10}{*}{ RR diastolic } & $\inf I$ & 0.30 & 11.82 & 0.00 & 10.95 & -0.84 & 14.63 & 0.00 & 11.11 & -0.52 & 0.606 & -0.07 \\
\hline & $\inf 2$ & -0.56 & 9.25 & 0.00 & 10.16 & 3.17 & 10.33 & 0.58 & 12.19 & -1.22 & 0.221 & -0.17 \\
\hline & $\inf 3$ & -3.19 & 16.07 & 0.00 & 17.92 & -2.80 & 12.76 & -7.14 & 23.93 & -0.04 & 0.971 & -0.01 \\
\hline & $\inf 4$ & -2.92 & 10.82 & -1.34 & 16.79 & 1.85 & 8.56 & 0.00 & 8.33 & -1.58 & 0.114 & -0.23 \\
\hline & $\inf 5$ & -0.34 & 11.05 & -1.75 & 10.53 & 0.21 & 10.35 & 0.00 & 16.16 & $-0.4 I$ & 0.684 & -0.06 \\
\hline & $\inf 6$ & -0.36 & 8.96 & 0.00 & 8.85 & 2.31 & 10.81 & -0.74 & 4.37 & -0.17 & 0.868 & -0.02 \\
\hline & $\inf 7$ & -2.03 & 9.79 & -2.38 & 6.43 & -0.93 & 11.18 & 0.00 & 8.93 & -0.71 & 0.479 & -0.10 \\
\hline & $\inf 8$ & -1.34 & 9.24 & -1.37 & 11.24 & -3.48 & 10.14 & 0.00 & 16.69 & -0.15 & 0.883 & -0.02 \\
\hline & & \multicolumn{4}{|c|}{ Non-antipsychotics $(n=32)$} & \multicolumn{4}{|c|}{ Antipsychotic drugs $(n=17)$} & & & \\
\hline & & M & SD & $\mathrm{Me}$ & IQR & M & SD & $\mathrm{Me}$ & IQR & Z & $\mathrm{P}$ & r \\
\hline \multirow[t]{8}{*}{$\mathrm{HR}$} & $\inf I$ & -3.11 & 13.43 & -1.65 & 13.24 & -1.82 & 6.55 & -1.45 & 6.03 & -0.21 & 0.834 & -0.03 \\
\hline & $\inf 2$ & -1.01 & 8.51 & -1.33 & 6.71 & -1.90 & 6.69 & -2.02 & 10.26 & -0.15 & 0.880 & -0.02 \\
\hline & $\inf 3$ & -2.25 & 9.74 & -1.15 & 12.97 & $-0.5 I$ & 7.45 & 0.00 & 7.44 & -0.36 & 0.721 & -0.05 \\
\hline & $\inf 4$ & -0.69 & 8.96 & 0.00 & 5.80 & -6.96 & 12.89 & -3.13 & 9.77 & -2.42 & 0.016 & -0.35 \\
\hline & $\inf 5$ & -1.46 & 9.33 & -1.39 & 9.42 & -3.20 & 9.61 & -1.45 & 12.63 & -0.42 & 0.674 & -0.06 \\
\hline & $\inf 6$ & -1.99 & 9.31 & -1.43 & 9.91 & -2.07 & 8.41 & -3.09 & 9.47 & -0.28 & 0.776 & -0.04 \\
\hline & $\inf 7$ & 0.26 & 9.60 & 0.00 & 11.86 & -3.42 & 9.84 & -2.78 & 14.47 & -0.91 & 0.365 & -0.13 \\
\hline & $\inf 8$ & -0.7 I & 9.80 & 0.00 & 9.59 & -6.16 & 15.29 & -5.06 & 7.89 & -1.68 & 0.093 & -0.24 \\
\hline \multirow[t]{8}{*}{ RR systolic } & $\inf I$ & 1.33 & 10.11 & 0.00 & 7.60 & -3.43 & 8.52 & -1.34 & 10.82 & -1.07 & 0.284 & -0.15 \\
\hline & $\inf 2$ & 0.21 & 9.79 & -0.72 & 15.24 & 0.15 & 5.85 & 0.00 & 6.55 & -0.10 & 0.923 & -0.01 \\
\hline & $\inf 3$ & 1.61 & 9.17 & 1.16 & 7.39 & -2.11 & 8.57 & -2.80 & 8.16 & $-|.8|$ & 0.071 & -0.26 \\
\hline & $\inf 4$ & -3.30 & 8.05 & -2.42 & 9.04 & -3.47 & 6.28 & -3.70 & 8.65 & -0.37 & 0.713 & -0.05 \\
\hline & $\inf 5$ & -1.02 & 7.37 & 0.00 & 5.73 & 1.26 & 12.17 & -1.56 & 13.14 & -0.26 & 0.796 & -0.04 \\
\hline & $\inf 6$ & 27.97 & 160.91 & 0.00 & 8.20 & 0.84 & 8.96 & 0.00 & 10.00 & -0.10 & 0.922 & -0.01 \\
\hline & $\inf 7$ & -1.03 & 11.13 & 0.00 & 14.99 & -1.05 & 5.12 & 0.00 & 7.70 & -0.01 & 0.990 & 0.00 \\
\hline & $\inf 8$ & -1.53 & 8.62 & -2.18 & 10.06 & -3.92 & 12.89 & -0.91 & 9.21 & -0.22 & 0.825 & -0.03 \\
\hline \multirow[t]{10}{*}{ RR diastolic } & $\inf I$ & 3.00 & 12.48 & 0.00 & 10.11 & -5.52 & 10.27 & -4.55 & 12.62 & -2.10 & 0.035 & -0.30 \\
\hline & $\inf 2$ & 0.46 & 9.12 & 0.00 & 15.73 & -0.23 & 10.42 & 0.00 & 7.63 & -0.31 & 0.754 & -0.04 \\
\hline & $\inf 3$ & -3.23 & 16.46 & 0.00 & 21.32 & -2.87 & $|3.2|$ & -4.49 & 13.14 & -0.76 & 0.449 & -0.11 \\
\hline & $\inf 4$ & -1.97 & 10.72 & 0.00 & 13.19 & $-|.6|$ & 10.31 & 0.00 & 20.33 & -0.14 & 0.891 & -0.02 \\
\hline & $\inf 5$ & -0.68 & 11.18 & 0.00 & 13.10 & 0.60 & 10.36 & 0.00 & 7.67 & -0.27 & 0.787 & -0.04 \\
\hline & $\inf 6$ & 0.91 & 10.11 & 0.00 & 12.62 & -1.23 & 7.60 & 0.00 & 6.20 & -0.22 & 0.825 & -0.03 \\
\hline & $\inf 7$ & -0.96 & 11.89 & 0.00 & 6.74 & -3.37 & 4.76 & -2.50 & 4.88 & $-0.6 I$ & 0.544 & -0.09 \\
\hline & $\inf 8$ & -1.78 & 9.67 & -0.75 & 10.62 & -1.95 & 9.21 & -0.63 & 15.40 & -0.01 & 0.990 & 0.00 \\
\hline & & \multicolumn{5}{|c|}{ No mood stabilizers $(n=27)$} & \multicolumn{3}{|c|}{ Mood stabilizers $(n=22)$} & & & \\
\hline & & M & SD & $\mathrm{Me}$ & $\mathrm{IQR}$ & M & SD & $\mathrm{Me}$ & IQR & Z & $\mathrm{P}$ & r \\
\hline \multirow[t]{4}{*}{ HR } & $\inf I$ & -3.15 & 13.90 & -1.69 & 14.29 & -2.06 & 7.74 & -1.53 & -3.15 & -0.14 & 0.888 & -0.02 \\
\hline & $\inf 2$ & -3.77 & 6.40 & -2.78 & 6.36 & 1.57 & 8.55 & 0.68 & -3.77 & -2.30 & 0.022 & -0.33 \\
\hline & $\inf 3$ & -2.00 & 9.98 & 0.00 & 12.24 & -1.21 & 7.75 & -1.40 & -2.00 & -0.42 & 0.673 & -0.06 \\
\hline & $\inf 4$ & -1.47 & 8.07 & 0.00 & 5.67 & -4.57 & $|3.4|$ & -1.21 & -1.47 & -0.77 & 0.445 & -0.11 \\
\hline
\end{tabular}

(Continued) 
Table 5 (Continued).

\begin{tabular}{|c|c|c|c|c|c|c|c|c|c|c|c|c|}
\hline & & \multicolumn{4}{|c|}{ Non-HA $(n=33)$} & \multicolumn{4}{|c|}{ HA $(n=16)$} & \multirow[t]{2}{*}{$\mathbf{Z}$} & \multirow[t]{2}{*}{$\mathbf{p}$} & \multirow[t]{2}{*}{$\mathbf{r}$} \\
\hline & & $\mathbf{M}$ & SD & Me & IQR & $\mathbf{M}$ & SD & Me & IQR & & & \\
\hline & $\inf 5$ & 0.01 & 10.21 & -0.69 & 13.43 & -4.53 & 7.79 & -2.13 & 0.01 & -1.22 & 0.222 & -0.17 \\
\hline & $\inf 6$ & -1.36 & 8.76 & -1.40 & 9.34 & -2.80 & 9.28 & -2.94 & -1.36 & -0.62 & 0.535 & -0.09 \\
\hline & $\inf 7$ & 0.18 & 9.04 & 0.00 & 8.30 & -2.29 & 10.45 & -1.64 & 0.18 & -0.65 & 0.513 & -0.09 \\
\hline & $\inf 8$ & -2.06 & 9.88 & -2.88 & $13.6 \mid$ & -3.32 & 14.29 & -1.23 & -2.06 & -0.46 & 0.648 & -0.07 \\
\hline \multirow[t]{8}{*}{ RR systolic } & $\inf I$ & 1.37 & 10.54 & 0.00 & 6.80 & -2.39 & 8.50 & -1.48 & 1.37 & -1.14 & 0.256 & -0.16 \\
\hline & $\inf 2$ & 1.22 & 9.86 & 0.38 & 12.67 & -1.04 & 6.66 & -1.11 & 1.22 & -1.11 & 0.268 & -0.16 \\
\hline & $\inf 3$ & 0.11 & 10.81 & 0.00 & 16.67 & 0.58 & 6.53 & 0.00 & 0.11 & -0.32 & 0.748 & -0.05 \\
\hline & $\inf 4$ & -1.76 & 5.90 & $-1.6 \mid$ & 7.14 & -5.32 & 8.68 & -4.92 & -1.76 & -1.78 & 0.075 & -0.25 \\
\hline & $\inf 5$ & 1.59 & 9.98 & 0.00 & 12.35 & -2.34 & 8.12 & $-1.6 \mid$ & 1.59 & -0.98 & 0.325 & -0.14 \\
\hline & $\inf 6$ & 0.13 & 5.61 & 0.00 & 7.88 & 41.14 & 194.07 & 0.00 & 0.13 & -0.05 & 0.959 & -0.01 \\
\hline & $\inf 7$ & 0.79 & 5.53 & 0.80 & 6.63 & -2.86 & 11.91 & -2.86 & 0.79 & -1.75 & 0.080 & -0.25 \\
\hline & $\inf 8$ & -2.06 & 12.16 & 0.00 & 12.10 & -2.82 & 8.50 & -3.82 & -2.06 & -1.17 & 0.241 & -0.17 \\
\hline \multirow[t]{8}{*}{ RR diastolic } & $\inf I$ & -0.11 & 13.68 & -2.78 & 9.44 & 0.23 & 10.80 & 0.00 & -0.11 & -0.64 & 0.519 & -0.09 \\
\hline & $\inf 2$ & 0.43 & 8.36 & 0.00 & 10.09 & -0.04 & 10.89 & -1.25 & 0.43 & -0.49 & 0.625 & -0.07 \\
\hline & $\inf 3$ & -1.12 & 12.44 & 0.00 & 12.69 & -5.54 & 18.16 & -6.36 & -1.12 & -0.83 & 0.410 & -0.12 \\
\hline & $\inf 4$ & 0.31 & 8.75 & 0.00 & 10.53 & -4.50 & 11.93 & -2.05 & 0.31 & -1.45 & 0.148 & -0.21 \\
\hline & $\inf 5$ & 0.44 & 10.61 & 0.00 & 13.69 & -1.02 & 11.23 & -2.83 & 0.44 & -0.64 & 0.520 & -0.09 \\
\hline & $\inf 6$ & -0.30 & 7.46 & -0.63 & 6.12 & 0.78 & 11.29 & 0.00 & -0.30 & -0.70 & 0.484 & -0.10 \\
\hline & $\inf 7$ & -1.28 & 4.72 & 0.00 & 4.47 & -2.36 & 13.40 & -2.50 & -1.28 & -1.00 & 0.318 & -0.14 \\
\hline & $\inf 8$ & 2.06 & 8.38 & 1.16 & 11.61 & -5.76 & 8.84 & -7.14 & 2.06 & $-2.6 \mathrm{I}$ & 0.009 & -0.37 \\
\hline
\end{tabular}

mood stabilizers and antipsychotic medication, but not selective serotonin-noradrenaline reuptake inhibitors (SNRIs), were associated with a significant decrease of HR and/or RR while ketamine infusion took place. Although, similar effects can be suggested, the changes were not significant and patients taking dose groups of medication should not be ruled out of the ketamine treatment.

The maximum value was reached at ca. 40 minutes after the start of administration in most of the trials and usually returned to the baseline (predose -0 ') range by 1.5 hours after administration. ${ }^{17-19}$ In some studies, the side effects are mild or moderate, well-tolerated and transient as all of them cease within 4 hours post administration. ${ }^{20}$

Our study is in line with esketamine trials ${ }^{17-19}$ as it was shown to produce no harm with esketamine treatment and all of the patients only experienced any persistent dissociative or psychotic symptoms during follow-up visits.

Our study replicates previously shown data in a study by Doherty et al, 2020, where esketamine nasal spray was administered to TRD patients. ${ }^{21}$ The results described here provide reassurance on the cardiovascular safety of IV ketamine, when administered to patients without hypertension or with controlled hypertension and under the observation of a physician. Although, there is currently a scientific debate on the validity and strength of the data in favor of this drug, ${ }^{22}$ patient screening and careful monitoring of BP and cardiovascular functioning are important during the time patients are receiving treatment with esketamine. Patients with cardiovascular diseases should not be treated with ketamine if the risk outweighs the benefits in this population, but regardless of psychotropic medication taken it seems safe and well tolerated.

\section{Limitation}

The methodological strength of our study was to strengthen the point that the tolerability and general safety of the administration of the drug and that result being in support with some previous ketamine studies mentioned above.

The key study limitations include small sample size and lack of randomization with the intervention blinding. Thus, it may be underpowered and its results shall be treated with caution as observational design does not warrant comparative or causative conclusions. The observations apply to treatment-resistant depression and include both MDD and bipolar depressed patients with a 
proportion of subjects diagnosed with somatic comorbidities and concomitant medication. Thus, the study population is inhomogeneous and represents subjects attending a tertiary-reference center. All safety and tolerability findings shall be replicated in a larger sample exposed to the intervention across the long-term study design.

\section{Conclusions}

The study results demonstrate good safety and tolerability profile of cardiovascular adverse drug reactions with shortterm treatment with intravenous ketamine as add-on intervention to current standard-of-care psychotropic medication in TRD. The abatement of elevated HR and BP was observed at the time of the treatment with no sequelae nor harm. The side effects are mild or moderate, well-tolerated and transient as all of them cease within 4 hours post administration. The study results corroborate with the current state of knowledge contributing to the safety/tolerability data on ketamine use, in particular in bipolar disorder where very little published reports are available to date. ${ }^{16,23,24}$

\section{Funding}

This work is supported by the Medical University of Gdańsk, Poland (Grant No. ST-02-0039/07/221).

\section{Disclosure}

Dr. Joanna Szarmach has received research support from Actavis, Eli Lilly, Minerva Neurosciences, Sunovion Pharmaceuticals, KCR, Janssen, Otsuka, Apodemus, Cortexyme, Acadia, and reports grants from Medical University of Gdansk, during the conduct of the study; personal fees from Actavis, outside the submitted work.

Prof. Wiesław Jerzy Cubała has received research support from Actavis, Alkermes, Allergan, Angelini, Auspex, Biogen, Bristol-Myers Squibb, Cephalon, Eli Lilly, Ferrier, Forest Laboratories, Gedeon Richter, GW Pharmaceuticals, Janssen, KCR, Lundbeck, Orion, Otsuka, Sanofi, and Servier; he has served on speakers bureaus for Adamed, Angelini, AstraZeneca, BristolMyers Squibb, Celon, GlaxoSmithKline, Janssen, Krka, Lekam, Lundbeck, Novartis, Orion, Pfizer, Polfa Tarchomin, Sanofi, Servier, and Zentiva; has served as a consultant for Angelini, GW Pharmaceuticals, Janssen, KCR, Quintiles, Celon, and Roche, and reports grants, personal fees, non-financial support from Janssen, during the conduct of the study; grants from Alkermes, outside the submitted work.
Dr. Adam Włodarczyk has received research support from Actavis, Eli Lilly, Minerva Neurosciences, Sunovion Pharmaceuticals, KCR, Janssen, Otsuka, Apodemus, Cortexyme, Acadia, and reports personal fees from actavis,outside the submitted work.

Dr. Maria Gałuszko-Węgielnik has received research support from: Janssen, Servier, Alkermes, KCR, Lilly, Biogen, Celon.

The authors report no other potential conflicts of interest for this work.

\section{References}

1. Berman RM, Cappiello A, Anand A, et al. Antidepressant effects of ketamine in depressed patients. Biol Psychiatry. 2000;47(4):351-354. doi:10.1016/s0006-3223(99)00230-9

2. Correia-Melo FS, Argolo FC, Araújo-de-Freitas L, et al. Rapid infusion of esketamine for unipolar and bipolar depres- sion: a retrospective chart review. Neuropsychiatr Dis Treat. 2017. doi:10.2147/ NDT.S135623

3. Diazgranados N, Ibrahim L, Brutsche NE, et al. A randomized addon trial of an N-methyl-D-aspartate antagonist in treatment- resistant bipolar depression. Arch Gen Psychiatry. 2010;67(8):793. doi:10.1001/archgenpsychiatry.2010.90

4. McCloud TL, Caddy C, Jochim J, et al. Ketamine and other glutamate receptor modulators for depression in bipolar disorder in adults. Cochrane Database Syst Rev. 2015. doi:10.1002/14651858. CD011611.pub2

5. Szarmach J, Cubała WJ, Włodarczyk A, et al. Short-term ketamine administration in treatment-resistant depression: focus on cardiovascular safety. Psychiatr Danub. 2019. PMID: 3148878.

6. Sanacora G, Frye MA, McDonald W, et al. A Consensus Statement on the Use of Ketamine in the Treatment of Mood Disorders. JAMA Psychiatry. 2017;74(4):399-405. doi:10.1001/jamapsychiatry.2017.0080

7. Fedgchin M, Trivedi M, Daly EJ, et al. Efficacy and Safety of FixedDose Esketamine Nasal Spray Combined With a New Oral Antidepressant in Treatment-Resistant Depression: Results of a Randomized, Double-Blind, Active-Controlled Study (TRANSFORM-1). Int J Neuropsychopharmacol. 2019;22(10):616630. doi:10.1093/ijnp/pyz039

8. Traber DL, Wilson RD, Priano LL. Diferentiation of the cardiovascular efects of CI-581. Anesth Analg. 1968;47(6):769-778. doi:10.1213/00000539-196811000-00025

9. Miller R, Eriksson L, Fleisher L, Wiener-Kronish J, Cohen N, Young W. Miller's Anesthesia. 8th ed. Philadelphia: Elsevier; 2015.

10. Riva-Posse P, Reif CM, Edwards JA, et al. Blood pressure safety of subanesthetic ketamine for depression: a report on 684 infusions. $J$ Afect Disord. 2018;236:291-297. doi:10.1016/j.jad.2018.02.025

11. Wan LB, Levitch CF, Perez AM, et al. Ketamine safety and tolerability in clinical trials for treatment-resistant depression. $J$ Clin Psychiatry. 2015;76(3):247-252. doi:10.4088/JCP.13m08852

12. Poon SH, Sim K, Baldessarini RJ. Pharmacological approaches for treatment-resistant bipolar disorder. Curr Neuropharmacol. 2015;13 (5):592-604. doi:10.2174/1570159X13666150630171954

13. Chandler GM, Iosifescu DV, Pollack MH, Targum SD, Fava M. RESEARCH: validation of the massachusetts general hospital antidepressant treatment history questionnaire (ATRQ). CNS Neurosci Ther. 2010;16(5):322-325. doi:10.1111/j.1755-5949.2009.00102.x

14. Trivedi MH, Corey-Lisle PK, Guo Z, Lennox RD, Pikalov A, Kim E. Remission, response without remission, and nonresponse in major depressive disorder: impact on functioning. Int Clin Psychopharmacol. 2009;24(3):133-138. doi:10.1097/YIC.0b013e3283277614 
15. Young T. What exactly is a mood stabilizer? J Psychiatry Neurosci. 2004;29(2):87-88. PMCID: PMC383340.

16. Zheng W, Zhou Y-L, Liu W-J, et al. A preliminary study of adjunctive ketamine for treatment-resistant bipolar depression. $J$ Affect Disord. 2020;275:38-43. doi:10.1016/j.jad.2020.06.020

17. Daly EJ, Trivedi MH, Janik A, et al. Efficacy of esketamine nasal spray plus oral antidepressant treatment for relapse prevention in patients with treatment-resistant depression. JAMA Psychiatry. 2019;76(9):893. doi:10.1001/jamapsychiatry.2019.1189

18. Fedgchin M, Trivedi M, Daly EJ, et al. Efficacy and safety of fixed-dose esketamine nasal spray combined with a new oral antidepressant in treatment-resistant depression: results of a randomized, double-blind, activecontrolled study (TRANSFORM-1). Int $J$ Neuropsychopharmacol. 2019;22(10):616-630. doi:10.1093/ijnp/pyz039

19. Popova V, Daly EJ, Trivedi M, Cooper K, Lane R, Lim P. Efficacy and safety of flexibly dosed esketamine nasal spray combined with a newly initiated oral antidepre- ssant in treatment-resistant depression: a randomized double-blind active-controlled study. Am J Psychiatry. 2019;176:428-438. doi:10.1176/appi.ajp.2019.19020172
20. Short B, Fong J, Galvez V, Shelker W, Loo CK. Side- effects associated with ketamine use in depression: a systematic review. Lancet Psychiatry. 2018;5:65-78. doi:10.1016/S2215-0366(17)30272-9

21. Doherty T, Wajs E, Melkote R, Miller J, Singh JB, Weber MA. Cardiac safety of esketamine nasal spray in treatment-resistant depression: results from the clinical development program. CNS Drugs. 2020;34(3):299-310. doi:10.1007/s40263-020-00699-4

22. Gastaldon C, Papola D, Ostuzzi G, Barbui C. Esketamine for treatment resistant depression: a trick of smoke and mirrors? Epidemiol Psychiatr Sci. 2020;29:e79, 1-4. doi:10.1017/S2045796019000751

23. Lu BY, Agapoff JR, Olson DJ, Williams SE, Roller A, Goeberta D. Rapid and sustained improvement in treatment-refractory depression through use of acute intravenous ketamine and concurrent transdermal selegiline: A case series. J Affect Disord. 2020;262:40-42. doi:10.1016/j.jad.2019.10.050

24. Peyrovian B, McIntyre RS, Phan L, et al. Registered clinical trials investigating ketamine for psychiatric disorders. J Psychiatr Res. 2020;127:1-12. doi:10.1016/j.jpsychires.2020.03.020
Neuropsychiatric Disease and Treatment

\section{Publish your work in this journal}

Neuropsychiatric Disease and Treatment is an international, peerreviewed journal of clinical therapeutics and pharmacology focusing on concise rapid reporting of clinical or pre-clinical studies on a range of neuropsychiatric and neurological disorders. This journal is indexed on PubMed Central, the 'PsycINFO' database and CAS, and is the official journal of The International Neuropsychiatric Association (INA). The manuscript management system is completely online and includes a very quick and fair peer-review system, which is all easy to use. Visit http://www.dovepress.com/testimonials.php to read real quotes from published authors. 